\title{
Bone metabolism and hand grip strength response to aerobic versus resistance exercise training in non-insulin dependent diabetic patients
}

\author{
Fadwa M. Al-Shreef ${ }^{1}$, Osama H. Al-Jiffri' ${ }^{1}$, Shehab M. Abd El-Kader ${ }^{2}$
}

\author{
1. Department of Medical Laboratory Technology, Faculty of Applied Medical Sciences, King \\ Abdulaziz University. \\ 2. Department of Physical Therapy, Faculty of Applied Medical Sciences, King Abdulaziz University.
}

\begin{abstract}
Background: Diabetes mellitus has been shown in many studies to be associated with reduced bone mass and an increased risk of fracture. Currently, our understanding of how to use exercise effectively in diabetic patients in prevention of osteoporosis is incomplete and has prompted our interest to identify the type of effective osteogenic exercise.

Objective: The aim of this study was to compare the changes in handgrip strength and bone metabolism after 6 months between aerobic and resistance exercise training in non-insulin dependent diabetic patients in Jeddah area.

Materials and methods: One hundred non-insulin dependent diabetic male patients participated in this study and were divided into two equal groups; the first group (A) received aerobic exercise training, where the second group (B) received resistance exercise training. The program consisted of three sessions per week for six months.

Results: The mean values of serum calcium and Hand grip strength were significantly increased, while the mean values of parathyroid hormone were significantly decreased in both groups.Also, there were significant differences between mean levels of the investigated parameters in group (A) and group (B) after treatment.

Conclusion: Aerobic exercise training on treadmill is appropriate to improve markers of bone metabolism and hand grip strength in non-insulin dependent diabetic patients.

Keywords: Aerobic exercise, resistance exercise, bone mineral density, non-insulin dependent diabetes.

DOI: http://dx.doi.org/10.4314/ahs.v15i3.25

Cite as: Al-Shreef FM, Al-Jiffri OH, Abd El-Kader SM. Bone metabolism and hand grip strength response to aerobic versus resistance exercise training in non-insulin dependent diabetic patients. Afri Health Sci. 2015;15(3):896-901. doi: http:// dx.doi.org/10.4314/abs.v15i3.25
\end{abstract}

\section{Introduction}

Bone metabolism defects are observed in patients with type 2 diabetes more frequently than in age-matched healthy controls ${ }^{1}$. Various effects of type 2 diabetes on bone metabolism and bone turnover have been previously reported ${ }^{2-4}$. The incidence of type 2 diabetes and osteoporosis increases worldwide. It is well established that type 2 diabetes mellitus is associated with an increased incidence of osteoporosis and hip and vertebral fractures ${ }^{4,5}$. A relationship between diabetes and bone metabolism is becoming increasingly recognized ${ }^{4}$. Several studies indicated that hyperglycemia induced a low turnover bone with osteoblast dysfunction ${ }^{7,8}$. Previous

\section{Corresponding author: \\ Fadwa M. Al-Shreef \\ Department of Medical Laboratory Technology, Faculty of Applied Medical Sciences, King Abdulaziz University, P.O. Box 80324, Jeddah, 21589, Saudi Arabia. E. mail: salmuzain@kau.edu.sa}

studies showed that serum osteocalcin was elevated in patients on treatment for diabetes mellitus, while bone specific alkaline phosphatase was reduced .These findings suggest that hyperglycemia affects osteoblast function and bone formation ${ }^{9,10}$.

Diabetes and osteoporosis are common and complex disorders with an enormous health burden. These conditions can be often associated, especially in middle-age and elderly individuals, with a further worsening of the mortality and morbidity of affected patients ${ }^{4}$.This association is probably due to detrimental effects of impaired glucose metabolism on bone health as well as to an increased risk of falls or other traumas, frequently reported in diabetic patients ${ }^{11,12}$.

The handgrip strength was most importantly related to body composition (lean mass, fat mass and $\%$ fat). Bone mineral density (BMD) of lumbar spine (L1-L4), femoral neck, and total body mass were measured by dual-energy X-ray absorptiometry. Marian et al, suggested that strategies aiming to improve muscle strength and lean mass must contribute to the bone health ${ }^{13}$. 
The prevalence and risk for osteoporosis among women $\geq 50$ years old is estimated to increase to approximately 35 million, by the year $2015^{14}$. While there are many pharmacologic agents available for the prevention of osteoporosis, widespread and long term use of these agents is limited due to side-effects, $\operatorname{costs}^{15}$ and poor long term compliance ${ }^{16}$. Therefore, it is essential that non-pharmacologic strategies to prevent osteoporosis continue to be evaluated ${ }^{17}$.

The American College of Sports Medicine (ACSM) recommends regular weight-bearing endurance activities in conjunction with resistance activities for preserving bone mass ${ }^{18}$. While, Greendale et al, proved that physical activity seems to stimulate bone accretion in a dose-dependent manner with a low threshold home activity are important for osteoporosis prevention ${ }^{19}$. Therefore, the aim of this study was to compare the changes in handgrip strength and bone metabolism after 6 months between aerobic and resistance exercise training in non-insulin dependent diabetic patients in Jeddah area.

\section{Patients and methods \\ Subjects}

One hundred non-insulin dependent diabetic male patients were enrolled in this study, their age ranged from 40 to 55 years. All volunteers were asked to read and sign an informed consent document prior to participation. Patients who are smokers, having any endocrine, musculoskeletal, renal, liver, cardiac disorders, obesity, chest diseases, any medication likely to influence bone metabolism or other pathologic processes were excluded. All participants were tested for serum calcium and parathyroid hormone before the treatment and after 6 months at the end of the study. Following pre-training testing, a randomized block procedure were used to assign qualified participants into 2 equal groups; group (A) received aerobic exercise training .The second group (B) received resisted exercise training. All participants were free to withdraw from the study at any time.

\section{Measurements}

\section{Laboratory analysis:}

Fasting venous blood samples were drawn between 7.30 and $9.30 \mathrm{a} . \mathrm{m}$. After collection, blood samples were collected in tubes containing EDTA, and serum samples were clotted at room temperature for $90 \mathrm{~min}$ and then centrifuged for $10 \mathrm{~min}$ at $1000 \times \mathrm{g}$. Samples were ali- quoted and stored at $-80^{\circ} \mathrm{C}$ until analysis. Parathyroid hormone $(\mathrm{PTH})$ and serum calcium: Intact PTH was measured in serum with an ELISA (Diagnostics Systems Laboratories, Inc., Webster, TX). The intra-assay CV was $5.0 \%$ and the inter-assay CV was $6.0 \%$.

\section{Grip strength assessment:}

Hand grip strength of the dominant hand was measured using three successive repetitions with a Jamar hand dynamometer (Sammons Preston Rolyan, Cedarburg, WI, USA). The elbow was flexed at a $90^{\circ}$ angle and not allowed to contact any body part. Resting time between subsequent measurements was 30 seconds $^{20}$. The mean value of the two best performances was used in the analyses. Hand grip was used as an index of general muscle strength.

Measurements of PTH, calcium and hand grip strength were taken before the starting of the study (pre-test) and after six months at the end of the study (post-test).

\section{Procedures}

Following the previous evaluation, all patients were divided randomly into the following groups:

1. Patients in group (A) were submitted to a $40 \mathrm{~min}$ aerobic session on a treadmill (the initial, 5-minute warm-up phase performed on the treadmill (Track master 400E, gas fitness system, England) at a low load, each training session lasted 30 minutes and ended with 5-minute recovery and relaxation phase) either walking or running, based on heart rate, until the target heart rate was reached, according to American College of Sport Medicine guidelines. The program began with 10 min of stretching and was conducted using the maximal heart rate index (HRmax) estimated by: 220-age. First 2 weeks $=60-70 \%$ of HRmax, 3rd to 12 th weeks $=$ $70-80 \%$ of HRmax. ${ }^{21}$.

2. Patients in group (B) were submitted to a $40 \mathrm{~min}$ session of resistance training. The program began with 10 min of stretching and was conducted with exercises done on eight resistance machines (Nautilus Sports/ Medical Industries, Independence, VA, England). The resistance machines were used: chest press, bicep curl, triceps extension, lower back, abdominals, leg press, leg curl and leg extension. Subjects performed three sets of 8-12 repetitions, with $60 \mathrm{~s}$ of rest between each set. Resistance was increased by five pounds after the subject was able to complete three sets of eight repetitions 
on three consecutive days. Subjects were trained using between 60 and $80 \%$ of their one maximal repetition weight $(1-\mathrm{RM})^{22}$.

\section{Statistical analysis}

The mean values of PTH, calcium and hand grip strength obtained before and after three months in both groups were compared using paired " $\mathrm{t}$ " test. Independent " $t$ " test was used for the comparison between the two groups $(\mathrm{P}<0.05)$.

\section{Results}

The two groups were considered homogeneous regarding the baseline descriptive characteristics (Table 1).

Table (1): Comparison of clinical data between both groups.

\begin{tabular}{|l|c|c|}
\hline & Group (A) & Group (B) \\
\hline Age $($ year) & $47.76 \pm 5.32$ & $48.91 \pm 5.85$ \\
\hline BMI $\left(\mathrm{kg} / \mathrm{m}^{2}\right)$ & $30.74 \pm 3.61$ & $31.33 \pm 4.12$ \\
\hline Fat mass $(\mathrm{kg})$ & $20.31 \pm 4.11$ & $21.40 \pm 3.94$ \\
\hline HBA $\mathbf{c}(\%)$ & $6.92 \pm 1.35$ & $7.14 \pm 1.19$ \\
\hline Albumin $(\mathrm{gm} / \mathrm{dl})$ & $3.73 \pm 0.86$ & $3.87 \pm 0.78$ \\
\hline FPG $(\mathrm{mg} / \mathrm{dL})$ & $135.45 \pm 11.42$ & $137.60 \pm 10.43$ \\
\hline Hb $(\mathrm{gm} / \mathrm{dl})$ & $12.15 \pm 1.57$ & $12.04 \pm 1.31$ \\
\hline Total Bilirubin $(\mathrm{mg} / \mathrm{dl})$ & $1.41 \pm 0.76$ & $1.45 \pm 0.82$ \\
\hline SBP $(\mathrm{mm} \mathrm{Hg})$ & $125 \pm 12.63$ & $127 \pm 12.96$ \\
\hline DBP $(\mathrm{mm} \mathrm{Hg})$ & $83 \pm 7.92$ & $85 \pm 8.21$ \\
\hline TC $(\mathrm{mg} / \mathrm{dl})$ & 192.3012 .86 & 194.5313 .65 \\
\hline HDL-c $(\mathrm{mg} / \mathrm{dl})$ & 34.542 .71 & 33.352 .49 \\
\hline LDL-c $(\mathrm{mg} / \mathrm{dl})$ & 132.939 .78 & 133.278 .94 \\
\hline TG $(\mathrm{mg} / \mathrm{dl})$ & 154.1510 .21 & 155.619 .83 \\
\hline
\end{tabular}
BMI = Body Mass Index
$\mathbf{H b}=$ Hemoglobin
$\mathbf{S B P}=$ Systolic blood pressure
FPG $=$ Fasting Blood Glucose
HBA1c $=$ glycosylated hemoglobin
HDL-c $=$ High density lipoprotein cholesterol
DBP $=$ Diastolic blood pressure
$\mathbf{T C}=$ Total cholesterol
$\mathbf{T G}=$ Triglyceride

LDL-c $=$ Low density lipoprotein cholesterol

$\left.{ }^{*}\right)$ indicates a significant difference between the two groups, $\mathrm{P}<0.05$.

The mean values of serum calcium and hand grip strength were significantly increased, while the mean values of parathyroid hormone were significantly de- creased in group (A) received aerobic exercise training and group (B) received resistance exercise training (Table $2 \& 3)$. 
Table (2): Mean value and significance of Serum Calcium, Parathyroid Hormone and Hand grip strength in group (A) before and after treatment.

\begin{tabular}{|l|c|c|c|c|}
\hline & \multicolumn{2}{|c|}{ Mean + SD } & T-value & Significance \\
\cline { 2 - 3 } & Before & After & \\
\hline $\begin{array}{l}\text { Serum calcium } \\
(\mathrm{ng} / \mathrm{dl} \text { ) }\end{array}$ & $8.26 \pm 1.47$ & $10.91 \pm 1.36$ & 6.52 & $\mathrm{P}<0.05$ \\
\hline $\begin{array}{l}\text { Parathyroid } \\
\text { hormone (ng/dl) }\end{array}$ & $14.91 \pm 2.85$ & $11.52 \pm 2.61$ & 6.61 & $\mathrm{P}<0.05$ \\
\hline $\begin{array}{l}\text { Hand grip strength } \\
(\mathrm{mmHg})\end{array}$ & $138.45+8.61$ & $172.74+7.78$ & 8.93 & $\mathrm{P}<0.05$ \\
\hline
\end{tabular}

Table (3): Mean value and significance of Serum Calcium, Parathyroid Hormone and Hand grip strength in group (B) before and after treatment.

\begin{tabular}{|l|c|c|c|c|}
\hline & \multicolumn{2}{|c|}{ Mean + SD } & T-value & Significance \\
\cline { 2 - 3 } & Before & After & 3.41 & $\mathrm{P}<0.05$ \\
\hline $\begin{array}{l}\text { Serum calcium } \\
\text { (ng/dl) }\end{array}$ & $8.14 \pm 1.52$ & $9.37 \pm 1.42$ & 3.62 & $\mathrm{P}<0.05$ \\
\hline $\begin{array}{l}\text { Parathyroid } \\
\text { hormone (ng/dl) }\end{array}$ & $14.63 \pm 2.97$ & $13.12 \pm 2.75$ & $\mathrm{P}<0.05$ \\
\hline $\begin{array}{l}\text { Hand grip strength } \\
\text { (mmHg) }\end{array}$ & $134.98+7.96$ & $155.24+7.18$ & 5.25 & \\
\hline
\end{tabular}

Also, there were significant differences between mean levels of the investigated parameters in group (A) and group (B) after treatment (Table 4).

Table (4): Mean value and significance of Serum Calcium, Parathyroid Hormone and Hand grip strength in group (A) and group (B) after treatment.

\begin{tabular}{|l|c|c|c|c|}
\hline & \multicolumn{2}{|c|}{ Mean \pm SD } & T-value & Significance \\
\cline { 2 - 3 } & Group (A) & Group (B) & \\
\hline $\begin{array}{l}\text { Serum calcium } \\
\text { (ng/dl) }\end{array}$ & $10.91 \pm 1.36$ & $9.37 \pm 1.42$ & 3.34 & $\mathrm{P}<0.05$ \\
\hline $\begin{array}{l}\text { Parathyroid } \\
\text { hormone (ng/dl) }\end{array}$ & $11.52 \pm 2.61$ & $13.12 \pm 2.75$ & 3.16 & $\mathrm{P}<0.05$ \\
\hline $\begin{array}{l}\text { Hand grip strength } \\
\text { (mmHg) }\end{array}$ & $172.74+7.78$ & $155.24+7.18$ & 4.35 & $\mathrm{P}<0.05$ \\
\hline
\end{tabular}




\section{Discussion}

In recent decays, quality of life and life expectancy of non-insulin dependent diabetic patients have been improved by better quality in treatment. Recently, new concerns have been directed to the reduced bone density in non-insulin dependent diabetes mellitus becoming an escalating burden worldwide due to an increased in life expectancy. Also, non-insulin dependent diabetic patients have lower levels of fitness and strength than their healthy peers. The physical therapist, along with the non-insulin dependent diabetes mellitus care team, can assist in preparing an individual to begin or progress to a physical activity program that enhances fitness level, body composition and overall well-being. This study aimed to compare the effects of aerobic treadmill walking exercises and resistance exercises on markers of bone metabolism and hand grip strength in male patients with non-insulin dependent diabetes mellitus.

The results of the present study concerning the mean values of serum calcium were significantly increased, while the mean values of parathyroid hormone were significantly decreased in group (A) and group (B). Also, there were significant differences between mean levels of the investigated parameters in group (A) and group (B) after treatment. These results agreed with Bradney etal. and Welton etal. reported that weight-bearing exercise is critical to ensure adequate bone mass accrual in childhood and may be even more important than dietary calcium intake ${ }^{23,24}$. However, Lanyon etal., said that the exact mechanism by which weight loading increases bone mass is not known but is likely related to dynamic strains in bone tissue regulating bone formation and resorption. ${ }^{6}$ Unusually high strains and high strain rates are particularly osteogenic ${ }^{25}$.

Also, Lester etal. , conducted a previous study to determine whether aerobic, resistance, or combined aerobic and resistance exercise programs conducted over eight weeks and compared to a control group could produce changes in biochemical markers of bone turnover indicative of bone formation. Biomarkers of bone formation were increased in the resistance and combined groups, while biomarkers of bone resorption were decreased and increased, respectively, after training in all groups. Small changes in BMD were observed in the distal tibia in the Aerobic and Combined groups, respectively. The results of the present study demonstrate that participation in an eight week physical training program that incorporates a resistance component by previously inactive young women results in alterations in biomarkers of bone remodeling indicative of increased formation without substantial alterations in markers of resorption ${ }^{25}$.

Finally results of the present study concerning the mean values of hand grip strength were significantly increased in group (A) and group (B). Also, there were significant differences between mean levels of the investigated parameters in group (A) and group (B) after treatment. These results approved by Marin et al. ${ }^{26}$, stated that Body weight was strongly and positively related to BMD in all sites, but the most important component of body composition was lean mass, also significantly related to all BMD sites, whereas fat mass was weakly related to the femoral neck BMD. The handgrip strength was most importantly related to lumbar spine, femoral neck, and total body $\mathrm{BMD}^{13}$.

\section{Conclusion}

Aerobic exercise training on treadmill is appropriate to improvemarkers of bone metabolism and hand grip strength in patients with non-insulin dependent diabetic patients.

\section{Acknowledgment}

This project was funded by the Deanship of Scientific Research (DSR), King Abdulaziz University, Jeddah, under grant no. (210-290-1433). The authors, therefore, acknowledge with thanks DSR technical and financial support.

\section{References}

1. Hofbauer L, Brueck C, Singh S, Dobnig H. Osteoporosis in patients with diabetes mellitus. J Bone Miner Res 2007; 22: 1317- PubMed ;1328.

2. Oz S, Guven G, Kilicarslan A. Evaluation of bonemetabolism and bone mass in patients with type-2 diabetes mellitus. J Natl Med Assoc 2006; 98: 1598- PubMed ;1604.

3. Vestergaard P. Bonemetabolism in type 2 diabetes and role of thiazolidinediones. Curr Opin Endocrinol Diabetes Obes 2009; 16: 125-131.

4. Rasul S, Ilhan A, Wagner L, Luger A, Kautzky-Willer A. Diabetic Polyneuropathy Relates to Bone Metabolism and Markers of Bone Turnover in Elderly Patients With Type 2 Diabetes: Greater Effects in Male Patients. Gender Medicine 2012; 9(3):187 PubMed -196. 
5. Vestergaard P. Discrepancies in bone mineral density and fracture risk in patients with type 1 and type 2 diabetes - a meta-analysis. Osteoporos Int 2007; 18: 427- PubMed ;444.

6. Hippisley-Cox J, Coupland C. Predicting risk of osteoporotic fracture in men and women in England and Wales: prospective derivation and validation of Q Fracture Scores. BMJ 2009; 339: b4229.

7. Verhaeghe J, Suiker A, Nyomba B, Visser W, Einhorn $\mathrm{T}$, Dequeker J. Bone mineral homeostasis in spontaneously diabetic BB rats. II. Impaired bone turnover and decreased osteocalcin synthesis. Endocrinology 1989; 124: 573- PubMed ;582.

8. Gerdhem P, Isaksson A, Akesson K, Obrant K. Increased bone density and decreased bone turnover, but no evident alteration of fracture susceptibility in elderly women with diabetes mellitus. Osteoporosis Int 2005; 16: 1506- PubMed ;1512.

9. Kanazawa I, Yamaguchi T, Yamamoto M, Yamauchi M, Yano S , Sugimoto T. Adiponectin is associated with changes in bone markers during glycemic control in type 2 diabetes mellitus. J Clin Endocrinol Metab 2009; 94:3031-3037.

10. Okazaki R, Totsuka Y, Hamano K, Ajima M, Miura M. Hirota Y. Metabolic improvement of poorly controlled noninsulin-dependent diabetes mellitus decreases bone turnover. J Clin Endocrinol Metab 1997; 82: 2915-2920.

11. Giaccari A, Sorice G, Muscogiuri G. Glucose toxicity: the leading actor in the pathogenesis and clinical history of type 2 diabetes - mechanisms and potentials for treatment. Nutr Metab Cardiovasc Dis 2009; 19 (5): 365-377.

12. Maurer M, Burcham J, Cheng H. Diabetes mellitus is associated with an increased risk of falls in elderly residents of a long-term care facility. J Gerontol A Biol Sci Med Sci 2005; 60: 1157-1162.

13. Marin R, Pedrosa M, Moreira-Pfrimer L, Matsudo S, Lazaretti-Castro M. Association between Lean Mass and Handgrip Strength with Bone Mineral Density in Physically Active Postmenopausal Women. Journal of Clinical Densitometry 2010; 13: 96-101.

14. National Osteoporosis Foundation .1996 and 2015 Osteoporosis prevalence figures: state by state report, National Osteoporosis Foundation, Washington (DC), 1997.

15. Rossouw J, Anderson G, Prentice R, LaCroix A, Kooperberg C, Stefanick M. Risks and benefits of es- trogen plus progestin in healthy postmenopausal women: principal results from the Women's Health Initiative randomized controlled trial. JAMA 2002; 288: 321- PubMed ;333.

16. Weycker D, Macarios D, Edelsberg J, Oster G. Compliance with drug therapy for postmenopausal osteoporosis. Osteoporos Int 2006; 17: 1645- PubMed ;1652.

17. Hamilton C, Thomas S, Jamal S. Associations between leisure physical activity participation and cortical bone mass and geometry at the radius and tibia in a Canadian cohort of postmenopausal women. Bone 2010; 46: 774-779 PubMed .

18. Kohrt W, Bloomfield S, Little K, Nelson M, Yingling V. American College of Sports Medicine Position Stand: physical activity and bone health. Med Sci Sports Exerc 2004; 36: 1985-1996.

19. Greendale G, Huang M, Wang Y, Finkelstein J, Danielson M, Sternfeld B. Sport and home physical activity are independently associated with bone density. Med Sci Sports Exerc 2003; 35: 506-512.

20. Guyton A. Human Physiology and Mechanisms of disease, 7th ed., W. B. Saunders Company, Tokyo 1993: 610-612.

21. Robergs R, Landwehr R. The surprising history of the "HRmax $=220$-age" equation. J Exerc Physiol Online 2002; 5(2):1-10.

22. Ramalho A, de Lourdes Lima M, Nunes F, Cambuí Z, Barbosa C, Andrade A, Viana A, Martins M, Abrantes V, Aragão C, Temístocles M. The effect of resistance versus aerobic training on metabolic control in patients with type-1 diabetes mellitus. Diabetes Res Clin Pract 2006; 72(3):271-6.

23. Bradney M, Pearce G, Naughton G. Moderate exercise during growth in pre-pubertal boys: changes in bone mass, size, volumetric density and bone strength. J Bone Miner Res 1998; 13:1814 - PubMed ;1821

24. Welton D, Kemper H, Post G. Weight-bearing activity during youth is a more important factor for peak bone mass than calcium intake. J Bone Miner Res 1994; 9:1089 - PubMed ;1096

25. Lanyon L. Using functional loading to influence bone mass and architecture: objectives, mechanisms, and relationship with estrogen of the mechanically adaptive process in bone. Bone 1996; 18:37S -43S

26. Lester M, Urso M, Evans R, Pierce J, Spiering B, Maresh C, Hatfield D, Kraemer W, Nindl B. Influence of exercise mode and osteogenic index on bone biomarker responses during short-term physical training. Bone 2009; 45(4):768 PubMed -76. 